\title{
Role of Aggressivity on Reactivity and Craving before and after Cue Exposure in Recently Detoxified Alcoholics: Results from an Experimental Study
}

\author{
Sonnig S.W. Chiang Christian G. Schuetz Michael Soyka \\ Psychiatric Hospital of Munich University, Munich, Germany
}

\section{Key Words}

Alcoholism · Aggression · Craving · Cue exposure

\begin{abstract}
The role of aggressivity and cue exposure in induction of craving were investigated in a clinical setting. Thirty abstinent alcoholic patients were divided into a low and a high aggressive group based on scores on the physical aggression subscale of the Buss-Durkee Hostility Inventory and exposed to alcohol cues. Craving was measured by means of the Alcohol Craving Questionnaire (ACQ) and Visual Analogue Scales (VAS). Important findings are: (1) main effects of aggressivity on 'emotionality', 'purposefulness' and 'expectancy' of ACQ were very significant; (2) on 'drinking intention' and 'craving for alcohol' of VAS, aggressivity and cue exposure showed a significant interaction; (3) the main effect of cue exposure on heart rate also reached a significance level of 0.007 . The results were discussed in the context of the Classical, Operant Conditioning Theory, the Cognitive Craving Theory of Tiffany, Gilbert's STAR Model, and the SelfMedication Hypothesis
\end{abstract}

Copyright $@ 2001$ S. Karger AG, Basel

\section{Introduction}

Craving ('urge to drink') has been regarded to be one of the prominent characteristics of drug addiction [54], although the definition of craving remains controversial [3a, 15, 29, 39, 45, 48]. Increasing evidence, however, suggests that craving could play a central role in the development of addiction [9, 15, 43, 57]; it is an internal cue which may precipitate relapse. Cue reactivity in alcoholics is a difficult but promising research area [13] offering new options in psychosocial and biomedical research $[16$, $33,60]$.

Assessment of craving is difficult $[12,13,15,70]$. Conventionally, craving is often assessed by means of a $100 \mathrm{~mm}$ Visual Analogue Scale (VAS) [58]. Recently, a multidimensional concept of craving was elaborated [43, $65,66,67]$; it includes at least a cognitive, an emotional and a behavioral aspect [43].

The source of craving was believed to reside in the addicts' 'personality rather than in his tissues' [4]. The significance of personality in developing alcoholism has been indicated by a number of authors [e.g. 10, 21, 56], although the relationship between craving and personality has rarely been examined in the past. Only recently, Wetterling et al. [72, 73a] postulated personality as one of the salient conditions for the occurrence of craving, and Gilbert [17] attempted to integrate personality features as

Michael Soyka, MD

Psychiatric Hospital of Munich University

Nussbaumstrasse 7, D-80336 München (Germany)

Tel. +49 8951605324, Fax +498951605617

E-Mail michael.soyka@psy.uni-muenchen.de
Fax + 41613061234

www.karger.com
Accessible online at:

www. karger.com/journals/ear 
important interceptive factors with possible impact on craving in his Situation-Trait-Adoptive-Response (STAR) Model.

An association between aggressive, antisocial behavior and drug abuse has repeatedly been shown [42]. Aggressive behavior has been observed to be extensively correlated with heavy alcohol use [8]. Empirical evidence [2, $44,51]$ as well as theoretical reviews [19, 40, 61] suggest that high behavioral activity level, impulsivity, inattention and aggressivity are associated with an increased risk for alcohol and drug abuse. Workman and Beer [75] investigated 134 high-school students and found that aggressivity scores were significantly and positively correlated with alcohol consumption. The importance of aggressivity in alcoholism has repeatedly been indicated by Alonso [1]; he described aggressivity as a prealcoholic personality and pointed at a close relationship between chronic alcoholism and aggressivity. Lately, Mann et al. [34] studied 258 male alcoholic patients and found aggressiveness to be associated with an early onset of alcohol dependence. Adolescents who use or abuse alcohol and other drugs often manifest aggressive and violent behavior [7]. A subgroup of alcoholics with enhanced aggression disposition was also found by Klages [27], Varma et al. [71], Bergman and Brismar [5], and Branchey et al. [6]. Several longitudinal and retrospective studies have documented an association between premorbid aggression and an increased risk for an alcohol-use disorder in adulthood. The results confirm the salience of aggressivity as an essential feature of this early-onset alcohol-abusing population [41].

In humans a low serotonin (5-hydroxytryptamine [5HT]) syndrome model [31] suggests an association between CSF monoamine metabolite levels (5-hydroxyindoleacetic acid [5-HIAA]), blood glucose regulation and alcohol consumption. This syndrome is also characterized by the early onset of impulsive, externally directed aggressive behavior, alcohol abuse and a family history of type II alcoholism. The role of 5-HT in the control of alcohol craving, anxiety and aggression has also been indicated by Hammoumi et al. [22].

Animal studies show that knockout of the 5-HT1B gene in mice results in increased aggression, as well as alcohol and cocaine consumption [24]. Heinz et al. [23] studied the interaction of 5-HT transporter availability with 5-HT turnover rate and with behavior characteristics predisposing to excessive alcohol usage in 11 male rhesus monkeys. They demonstrated that monkeys with greater $\beta$-CIT binding and low 5-HIAA CSF concentrations were more aggressive and less sensitive to alcohol intoxication.
Low sensitivity to alcohol intoxication predicts subsequent alcohol abuse.

Since alcoholism and aggression are interrelated according to clinical observation and neurobiological findings and craving might promote relapse to alcohol drinking, does the induced craving of alcoholics vary with the magnitude of their aggressive tendency? This study was designed to examine the role of the tendency of physical aggression in induced craving in weaned alcohol inpatients.

\section{Method}

\section{Subjects}

Participants were 30 male hospitalized alcoholics of the Psychiatric Hospital of Munich University. Male patients only were chosen as subjects because of the higher prevalence of aggression in males [47, 52, 64]. Further significant inclusion criteria were: (1) fulfilled criteria for alcohol dependence according to DSM-IV [3b] and ICD-10 [73b]; (2) a completed detoxification, and (3) a minimum abstinence duration of 1 week. Exclusion criteria were abuse/dependence of psychotropic substances other than nicotine and alcohol, major psychiatric disorders other than alcoholism such as schizophrenia, affective disorders, suicidal risk, cognitive dysfunction, severe medical illness, and current use of psychotropic agents (neuroleptics, antidepressants and anxiolytics). Those who had difficulties to understand written and spoken German would be excluded as well.

\section{Design}

Level of aggressivity of subjects and the experimental manipulation were independent variables. The classification of subjects was done with the help of Cluster Analysis; they were, according to their propensity of aggression, divided into a high and a low aggressive group. Dependent variables included an objective indicator (heart rate) and subjective parameters (self-reported craving before and after cue exposure). The experimental design was an ANCOVA for repeated measurement; the between-subjects factor was aggressivity (low vs. high) and the within-subjects factor was the experimental manipulation (baseline vs. cue exposure). Because the mean ages of these two subgroups ( 41.5 vs. 47.1 years old) were significantly different $(p=0.04)$, the factor 'age' was used as a covariant in the analysis of the effects of aggressivity. The data were evaluated by means of the program package SPSS 9.0. Nevertheless, for the technical limitations of the pulse oximeter, instead of mean heart rate (MHR) a highest-heart-rate (HHR) paradigm was employed to assess the heart rate of subjects.

\section{Materials}

The Alcohol Withdrawal Scale (AWS) and Structured Clinical Interview for DSM-IV (SCID - German version [74]) were administered to exclude those patients who still experienced symptoms of alcohol withdrawal or suffered from psychiatric disorders other than alcoholism and nicotine dependence. The data about serious medical diseases would be retrieved from the patient files. The subscale 'Physical Aggression' of the Buss-Durkee Hostility-Guilt Inventory (BDHI - German version [28]) was used to measure aggression tendency. It consists of 10 yes-no questions and has a score ranging from 
Table 1. Means and standard deviations of demographic variables for both the low and high aggression groups

\begin{tabular}{|c|c|c|c|c|c|}
\hline & \multicolumn{5}{|c|}{ Tendency of aggression } \\
\hline & \multicolumn{2}{|c|}{$\operatorname{high}(n=14)$} & \multicolumn{2}{|c|}{ low $(n=16)$} & \multirow[t]{2}{*}{$\mathrm{p}$ values } \\
\hline & mean & SD & mean & SD & \\
\hline Age & 41.50 & 6.96 & 47.13 & 7.31 & $0.04 *$ \\
\hline Number of previous detoxifications & 1.71 & 1.07 & 1.88 & 1.54 & 0.75 \\
\hline Abstinence duration, days & 22.14 & 16.89 & 20.50 & 9.52 & 0.74 \\
\hline Alcohol consumption, drinks/day & 28.07 & 12.29 & 25.78 & 9.31 & 0.57 \\
\hline Education, years school & 9.57 & 3.03 & 11.75 & 4.34 & 0.13 \\
\hline
\end{tabular}

$* \mathrm{p}<0.05$
0 to 10 . The Alcohol Craving Questionnaire (ACQ - German version [53]) is a 7-point scale; it has four dimensions - emotionality (EMOT), purposefulness (PURP), compulsivity (COMP), and expectancy (XPCT). 'Emotionality' measures craving which is associated with negative emotions, 'purposefulness' the intention to drink alcohol, 'expectancy' the perceived positive effects which are linked with alcohol use, and 'compulsivity' represents the feeling of loss of control over alcohol ingestion. Each dimension contains 3 questions; for each dimension the score could vary from minimum 3 to maximum 21. ACQ was developed and validated by Tiffany [67]; it is based on a global theoretical basis. VAS is a $100-\mathrm{mm}$ long scale. VAS is frequently used to measure craving in clinical and experimental studies. It could be, depending on research goals, differently combined; in this study, 5 questions were included. Each obtained measure of VAS could vary between 0 and 100. Finally, the state anxiety subscale of the State Trait Anxiety Inventory (STAI - German version [30]) and the Profile of Mood States (POMS - German version [38]) were also employed to measure mood changes before and after cue exposure. BDHI, ACQ, VAS, STAI (State), and POMS are computerized; it could ameliorate the reliability of the measurement through reducing some unsystematic mistakes such as missing and double marking.

\section{Procedure}

The study was divided into a screening, a habituation and an experimental phase. The screening phase began with checking patient files to identify those patients who had completed detoxification and whose AWS scores were less than 4. After a written informed consent was obtained, the experimenter conducted an interview using SCID. The self-rating personality scale BDHI (physical aggression) was also performed.

The experiment took place between 5 and 9 p.m. when most subjects usually drank alcohol. After being attached to a pulse oximeter, the subject was first required to close his eyes and to relax for $3 \mathrm{~min}$ until his actual pulse approximated to his normal one $( \pm 5)$. The baseline measurement with ACQ, VAS, POMS, STAI (State scale) and peak heart were conducted. The second section of the experiment was a cue exposure phase; the subject was required to imagine a scene regarding his usual drinking situation for $3 \mathrm{~min}$ and then exposed to an alcohol-related film. Three minutes after the film demonstration, a bottle of his favorite beer, an opener, an empty beer glass, and 3 empty beer bottles were placed on the table standing directly in front of him within his eyesight. Another 3 min later, he opened the beer and poured it into the empty beer glass at the request
Table 2. STAI of low and high aggression groups measured at baseline and after cue exposure

\begin{tabular}{|c|c|c|c|c|c|}
\hline & \multicolumn{5}{|c|}{ Tendency of aggression } \\
\hline & \multicolumn{2}{|c|}{ high $(n=14)$} & \multicolumn{2}{|c|}{ low $(n=16)$} & \multirow{2}{*}{$\begin{array}{l}p \text { values } \\
\text { (H vs. } L)\end{array}$} \\
\hline & mean & SD & mean & SD & \\
\hline Baseline & 45.43 & 10.13 & 39.94 & 8.56 & 0.12 \\
\hline Exposure & 43.57 & 10.12 & 40.06 & 7.18 & 0.28 \\
\hline p-values (B vs. E) & 0.47 & & 0.90 & & \\
\hline
\end{tabular}

of the experimenter. Next he was required to hold the beer as near to his nose as possible without touching it and to smell it for another $3 \mathrm{~min}$. In the end he put down the beer glass within his vision and gave a second time his answers for ACQ, VAS, STAI, and POMS. Each time the questions of ACQ, VAS, STAI and POMS were presented randomly on the screen of a computer in order to control the memory and the habituation effect, because they were shown twice within $1 \mathrm{~h}$

\section{Results}

Thirty of 36 subjects have completed the experiment. A total of 6 dropped out before the experiment. The demographic variables (including age, number of detoxification and abstinence duration) did not show any statistically significant differences to each other ( $n=30$ vs. 6 ), except for daily alcohol intake and education; the 6 dropouts were significantly less educated ( 8.8 vs. 10.7 years) and they drank significantly more than those 30 subjects (56.5 vs. 26.9 standard drinks). The mean age of these 30 subjects was 44.5 years (SD 7.6; range 32-58) and the mean number of previous inpatient detoxifications was 1.8 (SD 1.3). They had visited school for 10.7 years (SD 
Table 3. POMS of low and high aggression groups measured at baseline and after cue exposure

\begin{tabular}{|c|c|c|c|c|c|c|}
\hline & & \multicolumn{5}{|c|}{ Tendency of aggression } \\
\hline & & \multicolumn{2}{|c|}{$\operatorname{high}(n=14)$} & \multicolumn{2}{|c|}{ low $(n=16)$} & \multirow{2}{*}{$\begin{array}{l}\mathrm{p} \text { values } \\
\text { (H vs. L) }\end{array}$} \\
\hline & & mean & SD & mean & SD & \\
\hline \multirow[t]{3}{*}{ Confusion } & Baseline & 10.21 & 4.33 & 8.00 & 2.76 & 0.10 \\
\hline & Exposure & 10.50 & 4.27 & 8.53 & 2.39 & 0.15 \\
\hline & $\mathrm{p}(\mathrm{B}$ vs. E) & 0.80 & & 0.46 & & \\
\hline \multirow[t]{3}{*}{ Fatigue } & Baseline & 13.29 & 7.37 & 11.56 & 6.62 & 0.51 \\
\hline & Exposure & 12.86 & 6.03 & 12.20 & 7.11 & 0.79 \\
\hline & p (B vs. E) & 0.78 & & 0.59 & & \\
\hline \multirow[t]{3}{*}{ Depression } & Baseline & 22.64 & 8.97 & 19.44 & 5.81 & 0.27 \\
\hline & Exposure & 21.71 & 10.03 & 19.60 & 4.69 & 0.48 \\
\hline & $\mathrm{p}(\mathrm{B}$ vs. E) & 0.68 & & 0.87 & & \\
\hline \multirow[t]{3}{*}{ Vigor } & Baseline & 17.57 & 5.91 & 18.75 & 5.98 & 0.66 \\
\hline & Exposure & 16.86 & 6.62 & 17.87 & 5.37 & 0.66 \\
\hline & $\mathrm{p}(\mathrm{B}$ vs. E) & 0.51 & & 0.61 & & \\
\hline
\end{tabular}

3.9). Two $(6.7 \%)$ of the 30 subjects were unemployed. Eighteen $(60 \%)$ were single when they were recruited. On average, they drank 26.9 standard drinks (SD 10.7) per day, 1 week before their admission in the clinic and had been abstinent for 21.3 days (SD 13.3). The demographic data of both low and high aggressive subgroups are listed in table 1 . No statistically significant differences were revealed except for mean age. The difference achieved a 0.05 statistical significance level; the high aggressive alcohol addicts (mean 41.5 years old) were significantly younger than the low aggressive ones (mean 47.4 years old).

Tables 2 and 3 conclude the values of state anxiety (STAI - State) and the scores on the Profile of Mood States (POMS) for both groups respectively; although the high aggressive alcoholics reported a higher level of state anxiety and depressive mood, no significant statistical differences were observed either between the low and high aggressive group or between the baseline measurement and cue exposure.

The results for the craving measurements (ACQ and VAS) at baseline and after cue exposure are summarized in tables 4 and 5.

The findings of the ACQ show, with or without cue exposure, a statistically clearly significant influence of aggressivity on 'emotionality' (EMOT) $\mathrm{F}(1,29)=7.3, \mathrm{p}=$ 0.01, 'purposefulness' (PURP) $\mathrm{F}(1,29)=14.3, \mathrm{p}=0.001$, and 'expectancy' (XPCT) $F(1,29)=10.7, p=0.003$. The alcoholics with high physical aggression significantly tended to agree with 'not being able to resist alcohol if they had some alcohol here', with 'wanting to drink alcohol so badly that they can almost taste it', and with 'feeling less irritable if they used alcohol now' (EMOT). The high aggression tending alcoholics were also significantly strongly inclined to report 'feeling less tense, less nervous, and less restless, if they used alcohol' (XPCT). Even more strongly were their responses to those 3 questions of 'purposefulness': the alcohol patients with high aggression propensity tended strongly to 'feel better if they could drink', to 'be going to drink as soon as possible' and to agree with 'drinking would put them in a better mood' (PURP). The main effect of cue exposure on the dimension 'purposefulness' (PURP) also shows a trend to be significant $F(1,29)=3.6, p=0.07$. After confrontation with their favorite beer, they did not as strongly as at baseline agree with that (1) they would feel better if they could drink, that (2) they are going to drink as soon as possible, and that (3) drinking would put them in a better mood.

However, the results of VAS are somehow mixed. On 'I have craving for alcohol' (VAS-crave) and 'I intend to drink alcohol soon' (VAS-intent) of VAS, cue exposure and aggressivity performed together a very significant interactive effect; the corresponding F values are $6.9(\mathrm{p}=$ $0.01)$ and $13.3(p=0.001)$ respectively. Similar to the outcomes of ACQ, the alcoholics with high aggression disposition also reported, despite various experimental manipulations, a stronger craving for alcohol and stronger inten- 


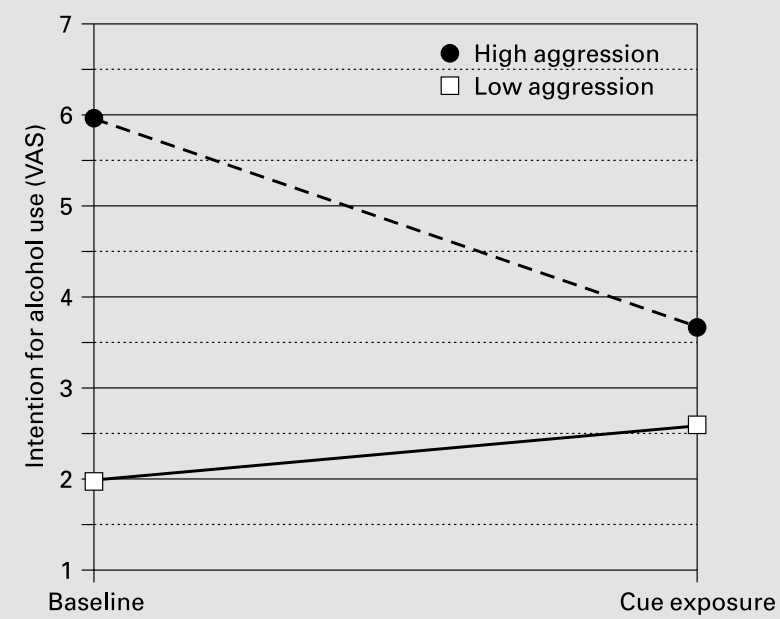

Fig. 1. The interactive effect between aggressivity and cue exposure on the question 'I intend to drink alcohol soon' of theVAS. The result showed here is modified with involving the factor 'age' as a covariant.

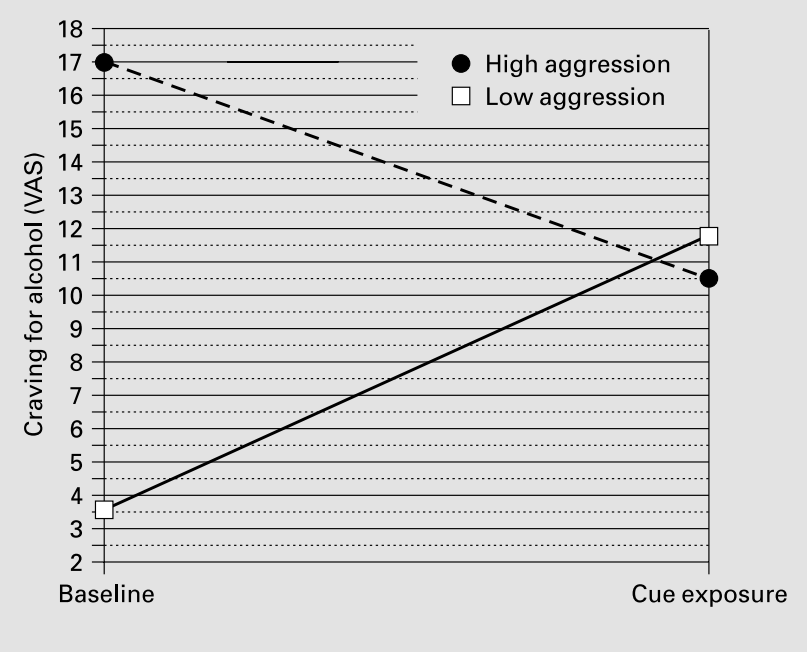

Fig. 2. The interactive effect between aggressivity and cue exposure on the question 'I have craving for alcohol' of theVAS. The result showed here is modified with involving the factor 'age' as a covariant.

Table 4. Means and standard deviations of the craving variables for both the low and high aggressive groups

\begin{tabular}{|c|c|c|c|c|c|c|c|c|}
\hline & \multicolumn{4}{|c|}{ Baseline } & \multicolumn{4}{|c|}{ Experiment } \\
\hline & \multicolumn{2}{|l|}{ high } & \multicolumn{2}{|l|}{ low } & \multicolumn{2}{|l|}{ high } & \multicolumn{2}{|l|}{ low } \\
\hline & mean & SD & mean & SD & mean & SD & mean & SD \\
\hline EMOT & 7.36 & 3.27 & 4.50 & 2.00 & 7.43 & 5.57 & 4.38 & 1.93 \\
\hline PURP & 8.00 & 4.64 & 4.13 & 1.50 & 8.00 & 4.69 & 3.69 & 1.14 \\
\hline COMP & 15.43 & 4.83 & 17.56 & 4.49 & 16.00 & 3.80 & 15.88 & 5.08 \\
\hline XРCT & 10.93 & 4.03 & 5.63 & 3.56 & 9.36 & 5.54 & 5.31 & 3.38 \\
\hline VAS-intent & 5.27 & 6.48 & 2.53 & 0.60 & 3.57 & 3.82 & 2.68 & 1.19 \\
\hline VAS-crave & 16.33 & 25.86 & 4.17 & 3.74 & 13.44 & 25.24 & 9.23 & 18.70 \\
\hline VAS-enjoy & 6.46 & 9.81 & 9.22 & 19.65 & 17.86 & 27.83 & 6.10 & 14.88 \\
\hline VAS-depre & 25.34 & 32.63 & 8.93 & 16.85 & 25.34 & 37.55 & 7.14 & 8.56 \\
\hline VAS-nerv & 34.69 & 32.43 & 16.07 & 21.90 & 28.57 & 33.04 & 9.52 & 14.57 \\
\hline Pulse/min & 79.43 & 5.77 & 87.00 & 11.60 & 90.43 & 8.41 & 95.25 & 12.01 \\
\hline
\end{tabular}

EMOT = Emotionality; PURP = purposefulness; COMP = compulsivity; XPCT = expectancy; VAS-intent = I intend to drink alcohol soon; VAS-crave = I have craving for alcohol; VAS-enjoy = I could enjoy drinking alcohol; VAS-depre = depressed; VAS-nerv = nervous; Score range for ACQ: 3-21; for VAS: $0-100$.

tion for alcohol ingestion. The craving (VAS-crave) of the high aggressive group was slightly reduced after cue exposure; contrarily, the alcohol craving of the low aggressive group increased slightly after confrontation with alcohol cues. Similar consequences were observed in their intention to drink alcohol (VAS-intent); the alcoholics with high aggressive tendency proclaimed to have less intention to alcohol use after cue exposure than at baseline. Nevertheless, the alcoholics with low aggressivity reacted to alcohol cues with slightly elevated drinking intention. In addition, the interactive effect between aggressivity and cue exposure on 'I could enjoy drinking alcohol' 
Table 5. Main effect of aggression and the interaction between aggression and cue exposure - summary of the results of ANCOVA for all craving variables

\begin{tabular}{|c|c|c|c|c|c|c|c|}
\hline $\begin{array}{l}\text { Question- } \\
\text { naire }\end{array}$ & Dimension & Sources & $\begin{array}{l}\text { Quadrate } \\
\text { sum }\end{array}$ & $\mathrm{df}$ & $\begin{array}{l}\text { Mean of } \\
\text { quadrate }\end{array}$ & $\mathrm{F}$ & $\begin{array}{l}\text { Signif- } \\
\text { icance }\end{array}$ \\
\hline \multirow[t]{12}{*}{ ACQ } & \multirow[t]{3}{*}{ EMOT } & $\mathrm{BE}$ & 2.20 & 1 & 2.20 & 0.29 & 0.59 \\
\hline & & Agg & 122.58 & 1 & 122.58 & 7.32 & $0.01^{* *}$ \\
\hline & & $\mathrm{BE} \times \mathrm{Agg}$ & 4.84E-02 & 1 & 4.84E-02 & 0.01 & 0.94 \\
\hline & \multirow[t]{3}{*}{ COMP } & $\mathrm{BE}$ & 13.45 & 1 & 13.45 & 0.85 & 0.37 \\
\hline & & Agg & 21.56 & 1 & 21.56 & 0.80 & 0.38 \\
\hline & & $\mathrm{BE} \times \mathrm{Agg}$ & 6.35 & 1 & 6.35 & 0.40 & 0.53 \\
\hline & \multirow[t]{3}{*}{ PURP } & $\mathrm{BE}$ & 4.52 & 1 & 4.52 & 3.61 & 0.07 \\
\hline & & Agg & 290.49 & 1 & 290.94 & 14.26 & $0.001 * * *$ \\
\hline & & $\mathrm{BE} \times \mathrm{Agg}$ & $5.78 \mathrm{E}-03$ & 1 & $5.78 \mathrm{E}-03$ & 0.01 & 0.95 \\
\hline & \multirow[t]{3}{*}{ XРCT } & $\mathrm{BE}$ & 6.30 & 1 & 6.30 & 0.75 & 0.39 \\
\hline & & Agg & 290.52 & 1 & 290.52 & 10.67 & $0.003 * *$ \\
\hline & & $\mathrm{BE} \times \mathrm{Agg}$ & 11.72 & 1 & 11.72 & 1.40 & 0.25 \\
\hline \multirow[t]{15}{*}{ VAS } & \multirow[t]{3}{*}{ VAS-intent } & $\mathrm{BE}$ & 19.57 & 1 & 19.57 & 9.72 & $0.004^{* *}$ \\
\hline & & Agg & 82.46 & 1 & 82.46 & 3.49 & 0.07 \\
\hline & & $\mathrm{BE} \times \mathrm{Agg}$ & 26.75 & 1 & 26.75 & 13.30 & $0.001 * * *$ \\
\hline & \multirow[t]{3}{*}{ VAS-crave } & $\mathrm{BE}$ & $1,037.17$ & 1 & $1,037.17$ & 10.31 & $0.003^{* *}$ \\
\hline & & Agg & 468.77 & 1 & 468.77 & 0.69 & 0.41 \\
\hline & & $\mathrm{BE} \times \mathrm{Agg}$ & 689.33 & 1 & 689.33 & 6.85 & $0.01 * *$ \\
\hline & \multirow[t]{3}{*}{ VAS-enjoy } & $\mathrm{BE}$ & 8.93 & 1 & 8.93 & 0.05 & 0.83 \\
\hline & & Agg & 124.31 & 1 & 124.31 & 0.23 & 0.64 \\
\hline & & $\mathrm{BE} \times \mathrm{Agg}$ & 665.24 & 1 & 665.24 & 334 & 0.08 \\
\hline & \multirow[t]{3}{*}{ VAS-depres } & $\mathrm{BE}$ & 12.25 & 1 & 12.25 & 0.03 & 0.86 \\
\hline & & Agg & $3,232.17$ & 1 & $3,232.17$ & 3.24 & 0.08 \\
\hline & & $\mathrm{BE} \times \mathrm{Agg}$ & 18.73 & 1 & 18.73 & 0.05 & 0.83 \\
\hline & \multirow[t]{3}{*}{ VAS-nerv } & $\mathrm{BE}$ & 185.26 & 1 & 185.26 & 0.51 & 0.48 \\
\hline & & Agg & $3,345.79$ & 1 & $3,345.79$ & 3.30 & 0.08 \\
\hline & & $\mathrm{BE} \times \mathrm{Agg}$ & 34.38 & 1 & 34.38 & 0.09 & 0.76 \\
\hline \multirow[t]{3}{*}{ Pulse, min } & & $\mathrm{BE}$ & 101.06 & 1 & 101.06 & 8.54 & $0.007 * *$ \\
\hline & & Agg & 177.70 & 1 & 177.70 & 1.03 & 0.32 \\
\hline & & $\mathrm{BE} \times \mathrm{Agg}$ & 10.76 & 1 & 10.76 & 0.91 & 0.35 \\
\hline
\end{tabular}

$\mathrm{BE}=$ Baseline/after cue exposure; $\mathrm{Agg}=$ aggression; $* * \mathrm{p}<0.01,{ }^{* * *} \mathrm{p}>0.001$.

In the results shown here, age was treated as a covariant.

(VAS-enjoy) of VAS also showed a trend to be significant $(F(1,29)=3.3 ; p=0.08)$. After cue exposure, the high aggressive alcoholics reported being much more able to enjoy drinking alcohol than at baseline while patients of the low aggressive group were opposite. Finally, the alcoholic patients with high aggression propensity tended to describe a higher level of depressed $\operatorname{mood}(\mathrm{F}=3.2)$ as well as a higher niveau of nervousness $(F=3.3)$; both main effects of aggressive tendency reach a 0.08 significance level.
Aggressivity did not appear to have any main effect or, together with cue exposure, an interactive effect on heart rate. However, exposition to their favorite beer alone did promote the heart frequency of both groups in a similar magnitude; the main effect of cue exposure achieved a $\mathrm{F}$ value of 8.5 which reaches a 0.007 significance level (fig. 1, 2). 


\section{Discussion}

The results of this experimental study on the possible influence of aggressivity on craving showed that alcoholics with high aggressive inclination reported subjectively (self-report) and objectively (heart rate) stronger craving than did patients with low aggressivity, independent from the performed experimental manipulations (baseline or cue exposure) and the employed craving measuring instruments (ACQ or VAS). The high aggressive alcoholics proclaimed (1) a higher level of craving (VAS) which is associated with negative affects (ACQ), agreed (2) to feel less bad through drinking alcohol (ACQ), and (3) had a stronger intention to drink alcohol soon (VAS \& ACQ). A small discrepancy between the outcomes of ACQ and those of VAS could result from different conceptualizations of both; each VAS question represents an independent and simple concept, while a dimension of ACQ includes 3 questions which form a more complex one.

The results of this study generally provide a preliminary support for Gilbert's STAR Model [17] and the model of Wetterling et al. [72]; both indicate personality as an interoceptive factor with impact on craving.

A possible explanation could be based on the Classical and Operant Conditioning Theory. In our study, the high aggressive tending alcohol patients associated alcohol with negative affects significantly more often and perceived the positive effects of alcohol much more strongly than did the low aggressive group, probably because they had more chances to be 'classically' (alcohol use $\rightarrow$ negative affects vanish) and 'operantly' (negative affects $\rightarrow$ drink alcohol) conditioned with alcohol ingestion, compared to those who are disposed with low aggressive propensity.

In addition, the subjects as inpatients were not allowed to drink alcohol during the experiment though being exposed to their favorite beer; this could lead to cognitive dissonance. A similar effect among hospitalized and before alcohol cues standing alcohol patients was likewise described in the study of Lipscomb and Nathan [32]. Such an ambivalent feeling ('to drink or not to drink') could induce craving according to Tiffany's Cognitive Craving Theory [65-67, 69] which postulates that if the scheme of alcohol consumption is obstructed, then craving develops. Tiffany's theory could generally explain why our subjects still experienced craving and did not feel to have total control over alcohol use while being confronted with alcohol cues in a clinic setting. They showed a strength of craving for alcohol ranging between
13 and 21 as well as a control over alcohol intake between 30 and 70, if the highest level of craving/control is deemed as 100 . Craving is also frequently associated with actual negative mood states such as depressive or disturbed mood and nervousness [33, 72]. The high aggressive subjects in this study showed a trend to be significantly more depressive and nervous than their low aggressive counterparts at baseline and after cue exposure as well; so they accordingly reported a higher level of craving and drinking intention to alcohol cues than did those alcoholics with low aggressive tendency. Since, in comparison to the low aggressive subjects, the alcohol dependents with high aggression tended to be more depressive and nervous and significantly strongly admitted that they would feel less tense, less nervous and less restless through using alcohol; self-medication could be another alternative to explain the phenomena 'high aggressivity, high alcohol craving'. Similar implications were also made in the STAR Model of Gilbert [17]; it posits that a depressive person tends to react depressively to abstinence and to consume substances to relieve depression.

The opposite reactions of the high and the low aggressive alcohol addicts towards alcohol cues (VAS) can possibly be a result of the change of state anxiety from baseline to cue exposure. A positive correlation between craving and anxiety in abstinent alcoholics was already indicated two decades ago by Mathew et al. [35]. The results of the STAI show that the high aggressive alcoholics became slightly less anxious after cue exposure, while those with low aggressivity were somewhat more anxious. The craving and the intention to alcohol use of both groups also seemed to be accordant with the changes of their state anxiety.

Accelerated heart frequency as a typical autonomic responding to alcohol cues was implied in numerous studies [e.g. 11, 25, 26, 36, 59]; their experimental designs, including features of subjects, cues, induction methods, differ from one another though. Therefore, heart rate is frequently deemed as a reliable indicator of cue reactivity in alcoholics [50]. Greeley et al. [20], Eriksen and Gotestam [14] and Pomerleau et al. [46] had yet converse implications. Our findings were accordant with the studies of Kaplan and others; both high and low aggressive alcoholics physiologically reacted to cue exposure with accelerated heart frequency. The magnitude of heart rate increment of both groups was not much different. It is noteworthy that a HHR paradigm was used in our study; it might overestimate the heart rate. In order to compensate the disadvantage of a HHR paradigm, behavior observation 
was conducted through the whole experiment; no overt differences were noticed between baseline and cue exposure.

In summary, the results of this study indicate a significant role of aggressivity in experimentally induced craving during the early abstinence phase. Future studies may address interrelationship between aggressivity as a personality trait, mood disturbances and reactivity to alcohol-related stimuli. Craving as a multidimensional concept [65-67], aggressivity is possibly a salient determinant in the development of the 3 craving dimensions - 'emotionality', 'purposefulness' and 'expectancy'. If craving is defined as an ambiguous concept, then both exposition to alcohol cues and the physical aggressive tendency of alcohol addicts could have impact on their subjective craving. To induce a physiological craving reaction, heart rate in this study, cue exposure alone seemed to play a major role. The outcomes of this study might offer further indicators to develop differential medical treatment of alcoholics as well as more individual coping strategies to deal with high-risk relapse situations.

\section{Acknowledgement}

This study was supported by a grant of the Hanns-Seidel Foundation.

\section{References}

1 Alonso FF: Aggressivität und Autoaggressivität bei Alkoholabhängigen/Aggressiveness and autoaggressiveness in alcoholics; in Nissen G(ed): Aggressivität und Gewalt. Prävention und Therapie. Würzburger Therapeutische Gespräche. Bern, Huber, 1995, vol 4, pp 119 127.

2 Alterman AI, Tarter RE, Petrarulo EW, Baughman TG: Evidence for impersistence in young male alcoholics. Alcohol Clin Exp Res 1984;8: 448-450.

3a Anton RF: What is craving? Models and implications for treatment. Alcohol Res Health 1999;23:165-173.

3b APA: Diagnostic and Statistical Manual of Mental Disorders, ed 4. Göttingen, Hogrefe, 1994.

4 Ausubel DP: Methadone maintenance treatment: The other side of the coin. Int J Addict 1983;18:851-862.

5 Bergman B, Brismar B: Hormone levels and personality traits in abusive and suicidal male alcoholics. Alcohol Clin Exp Res 1994;18:311316.

6 Branchey L, Branchey M, Shaw S, Lieber CS: Depression, suicide, and aggression in alcoholics and their relationship to plasma amino acids. Psychiatry Res 1984;12:219-226.

7 Bukstein OG: Aggression, violence, and substance abuse in adolescents. Child Adolesc Psychiatr Clin North Am 1996:5:93-109.

8 Buydens-Branchey L, Branchey MH: Cortisol in alcoholics with a disordered aggression control. Psychoneuroendocrinology 1992;17:4554

9 Ciccocioppo R: The role of serotonin in craving: From basic research to human studies. Alcohol Alcohol 1999;34:244-253.

10 Cloninger CR, Sigvardsson S, Gilligan SB, von Knorring AL, Reich T, Bohman M: Genetic heterogeneity and the classification of alcoholism. Adv Alcohol Subst Abuse 1988;7:3-16.
11 Cooney NL, Litt MD, Morse PA, Bauer LO, Gaupp L: Alcohol cue reactivity, negativemood reactivity, and relapse in treated alcoholic men. J Abnorm Psychol 1997;106:243250 .

12 DeWit H: Laboratory-based assessment of alcohol craving in social drinkers. Addiction 2000;95:165-169.

13 Drummond DC: What does cue reactivity have to offer clinical research? Addiction 2000;95: 129-144.

14 Eriksen L, Gotestam KG: Conditioned abstinence in alcoholics: A controlled experiment. Int J Addict 1984;19:287-294.

15 Flannery BA, Roberts AJ, Cooney N, Swift RM, Anton RF, Rohsenow DJ: The role of craving in alcohol use, dependence, and treatment. Alcohol Clin Exp Res 2001;25:299-308.

16 George MS, Anton RF, Bloomer C, Teneback C, Drobes DJ, Lorberbaum JP, Nahas Z, Vincent DJ: Activation of prefrontal cortex and anterior thalamus in alcoholic subjects of exposure to alcohol-specific cues. Arch Gen Psychiatry 2001;58:345-352.

17 Gilbert DG: The situation-trait adaptive response (STAR) model of drug use, effects, and craving. Hum Psychopharmacol 1997; 12(suppl 2):S89-S102.

18 Glautier S, Drummond DC: Alcohol dependence and cue reactivity. J Stud Alcohol 1994; 55:224-229.

19 Gorenstein EE, Newman JP: Disinhibitory psychopathology: A new perspective and a model for research. Psychol Rev 1980;87:301315.

20 Greeley JD, Swift W, Prescott J, Heather N: Reactivity to alcohol-related cues in heavy and light drinkers. J Stud Alcohol 1993;54:359368.

21 Gunderson JG, Phillips KA: Personality Disorders. Baltimore, Williams \& Wilkins, 1995, pp 1425-1462.
22 Hammoumi S, Naassila M, Daoust M: Experimental findings in the study of the reduction of alcohol intake. Eur Neuropsychopharmacol 1997;7(suppl 3):337-340.

23 Heinz A, Higley JD, Gorey JG, Saunders RC, Jones DW, Hommer D, Zajicek K, Suomi SJ, Lesch KP, Weinberger DR, Linnoila M: In vivo association between alcohol intoxication, aggression, and serotonin transporter availability in nonhuman primates. Am J Psychiatry 1998;155:1023-1028.

24 Huang YY, Grailhe R, Arango V, Hen R, Mann JJ: Relationship of psychopathology to the human serotonin-1B genotype and receptor binding kinetics in postmortem brain tissue. Neuropsychopharmacology 1999;21:238-246.

25 Kaplan RF, Cooney NL, Baker LH, Gillespie RA, Meyer RE, Pomerleau OF: Reactivity to alcohol-related cues: Physiological and subjective responses in alcoholics and nonproblem drinkers. J Stud Alcohol 1985;46:267-272.

26 Kaplan RF, Meyer RE, Stroebel CF: Alcohol dependence and responsivity to an ethanol stimulus as predictors of alcohol consumption. Br J Addict 1983;78(3):259-267.

27 Klages U: Cluster analysis of alcoholic patients based on personality variables, social insecurity and control orientation (abstract). Z Klin Psychol Psychopathol Psychother 1984;32: 260-270.

28 Kornadt HJ: Buss-Durkee-Fragebogen Hostility-Guilt Inventory; in Buss AH, Durkee A (eds): Aggressionsmotiv und Aggressionshemmung. Aggressions-TAT und andere aggresionsrelevante Verfahren (German version). Bern, Huber, 1957, vol 2, pp 138-141.

29 Kozlowski LT, Mann RE, Wilkinson DA, Poulos CX: 'Cravings' are ambiguous: Ask about urges or desires. Addict Behav 1989;14:443445. 
30 Laux L, Glanzmann P, Schaffner P, Spielberger CD: STAI State-Trait-Angstinventar; in Spielberger CD, Gorsuch RL, Lushene RE (eds): State-Trait Anxiety Inventory (German version). Weinheim, Beltz, 1970.

31 Linnoila VM, Virkkunen M: Aggression, suicidality, and serotonin. J Clin Psychiatry 1992; 53:46-51.

32 Lipscomb TR, Nathan PE: Blood alcohol level discrimination. The effects of family history of alcoholism, drinking pattern, and tolerance. Arch Gen Psychiatry 1980;37:571-576.

33 Litt MD, Cooney NL, Morse P: Reactivity to alcohol-related stimuli in the laboratory and in the field predict craving in treated alcoholics. Addiction 2000;95:889-900.

34 Mann K, Ackermann K, Jung M, Morlock P, Mundle G: Aggressiveness, onset of dependence, and treatment outcome in socially welladapted alcoholics. Alcohol Alcohol 1998;33: 16-19.

35 Mathew RJ, Claghorn JL, Largen J: Craving for alcohol in sober alcoholics. Am J Psychiatry 1979;136:603-606.

36 McCaul ME, Turkkan JS, Stitzer ML: Psychophysiological effects of alcohol-related stimuli. I. The role of stimulus intensity. Alcohol Clin Exp Res 1989;13:386-391.

37 McCusker CG, Brown K: The cue-responsivity phenomenon in dependent drinkers: 'Personality' vulnerability and anxiety as intervening variables. Br J Addict 1991;86:905-912.

38 McNair DM, Lorr M, Dropplemann LF, Bieh B, Dangel S: POMS profile of mood states Deutsche Bearbeitung von Biehl, Dangel \& Reiser (PSYTKOM-Dokumentation in Vorbereitung)/Profile of Mood States (German adaption/author). In Internationale Skalen für Psychiatrie (2. veränderte Auflage), Profile of Mood States. Ein Verfahren zur Messung von Stimmungszuständen. Selbstbeurteilungsskala In Collegium Internationale Psychiatriae Scalarum (CIPS). Weinheim, Beltz.

39 Meyer RE: Craving: What can be done to bring the insights of neuroscience, behavioral clinical science into synchrony. Addiction 2000;95: 219-227.

40 Moffitt TE: Adolescence-limited and lifecourse-persistent antisocial behavior: A developmental taxonomy. Psychol Rev 1993;100: 674-701.

41 Moss HB, Kirisci L: Aggressivity in adolescent alcohol abusers: Relationship with conduct disorder. Alcohol Clin Exp Res 1995;19:642-646.

42 Muntaner C, Walter D, Nagoshi C, Fishbein D, Haertzen CA, Jaffe JH: Self-report vs. laboratory measures of aggression as predictors of substance abuse. Drug Alcohol Depend 1990;25: $1-11$.

43 Newlin DB: A comparison of drug conditioning and craving for alcohol and cocaine. Recent Dev Alcohol 1992;10:47-64.

44 Pelham WE, Lang AR: Parental alcohol consumption and deviant child behavior: Laboratory studies of reciprocal effects. Clin Psychol Rev 1993;13:763-784.
45 Pickens RW, Johanson CE: Craving: Consensus of status and agenda for future research. Drug Alcohol Depend 1992;30:127-131.

46 Pomerleau OF, Fertig J, Baker L, Cooney N: Reactivity to alcohol cues in alcoholics and non-alcoholics: Implications for a stimulus control analysis of drinking. Addict Behav 1983;8:1-10.

47 Poorman P, Donnerstein E, Donnerstein M: Aggressive behavior as a function of age and sex. J Genet Psychol 1983;128:183-187.

48 Potgieter AS, Deckers F, Geerlings P: Craving and relapse measurement in alcoholism. Alcohol Alcohol 1983;34:254-260.

49 Prescott CA, Neale MC, Corey LA, Kendler KS: Predictors of problem drinking and alcohol dependence in a population-based sample of female twins. J Stud Alcohol 1997;58:167181

50 Rajan I, Murthy PJ, Ramakrishnan AG, Gangadhar BN, Janakiramaiah N: Heart rate variability as an index of cue reactivity in alcoholics. Biol Psychiatry 1998;43:544-546.

51 Reich W, Earls F, Frankel O, Shayka JJ: Psychopathology in children of alcoholics. J Am Acad Child Adolesc Psychiatry 1993;32:9951002.

52 Richardson DC, Bernstein S, Taylor SP: The effect of situational contingencies on female retaliative behavior. J Pers Soc Psychol 1979; 37:2044-2048.

53 Schuetz CG, Koch J, Preuss U, Soyka M: Reliability and Validity of the German Version of the 47-Item Craving Questionnaire and the 49Item Addiction Research Center Inventory. Building International Research Infrastructure in the Field of Drug Abuse. Nashville, June 1920, 1997.

54 Self DW, Genova LM, Hope BT, Barnhart WJ, Spencer JJ, Nestler EJ: Involvement of cAMPdependent protein kinase in the nucleus accumbens in cocaine self-administration and relapse of cocaine-seeking behavior. J Neurosci 1998;18:1848-1859.

55 Sher KJ, Levenson RW: Risk for alcoholism and individual differences in the stress-response-dampening effect of alcohol. J Abnorm Psychol 1982;91:350-367.

56 Sher KJ, Trull TJ: Personality and disinhibitory psychopathology: Alcoholism and antisocial personality disorder. J Abnorm Psychol 1994; 103:92-102.

57 Sinha R, O'Malley SS: Craving for alcohol: Findings from the clinic and the laboratory. Alcohol Alcohol 1999;34:223-230.

58 Soyka M: Die Alkoholkrankheit. Weinheim/ London, Chapman \& Hall, 1995.

59 Stormark KM, Laberg JC, Bjerland T, Nordby $\mathrm{H}$, Hugdahl $\mathrm{K}$ : Autonomic cued reactivity in alcoholics: The effect of olfactory stimuli. Addict Behav 1995;20:571-584.

60 Szegedi A, Lorch B, Scheurich A, Ruppe A, Hautzinger M, Wetzel H: Cue exposure in alcohol-dependent patients: Preliminary evidence for different cue reactivity. J Neural Transm 2000; 107:721-730.
61 Tarter R, Alterman A, Edwards K: Neurobehavioral theory of alcoholism etiology; in Chaudron C, Wilkinson D (eds): Theories of Alcoholism. Toronto, Addiction Research Foundation, 1989

62 Tarter RE, Alterman AI, Edwards KL: Alcoholic denial: A biopsychological interpretation. J Stud Alcohol 1984;45:214-218.

63 Tarter RE, Alterman AI, Edwards KL: Vulnerability to alcoholism in men: A behavior-genetic perspective. J Stud Alcohol 1985;46:329356.

64 Tieger T: On the biological basis of sex differences in aggression. Child Dev 1980;51:943963

65 Tiffany ST: A cognitive model of drug urges and drug-use behavior: Role of automatic and nonautomatic processes. Psychol Rev 1990;97: 147-168.

66 Tiffany ST: A critique of contemporary urge and craving research: Methodological, psychometric, and theoretical issues. Adv Behav Res Ther 1992;14:123-139.

67 Tiffany ST: The role of cognitive factors in reactivity to drug cues; in Drummond DC, Tiffany ST, Glautier S, Remington B (eds): Addictive Behaviours: Cue Exposure Theory and Practice. Chichester, Wiley, 1995, pp 137 165

68 Tiffany ST, Carter BL: Is craving the source of compulsive drug use? J Psychopharmacol 1998;12:23-30.

69 Tiffany ST, Singleton EG, Henningfield JE, Heisman SJ, Douglas TE: Multidimensional aspects of craving for alcohol. 57th Annual Scientific Meeting, College on Problems in Drug Dependence, 1995.

70 Tiffany ST, Carter BL, Singleton EG: Challenges in the manipulation, assessment and interpretation of craving relevant variables. Addiction 2000;95:177-187.

71 Varma VK, Basu D, Malhotra A, Sharma A, Mattoo SK: Correlates of early- and late-onset alcohol dependence. Addict Behav 1994;19: 609-619.

72 Wetterling T, Veltrup C, Junghanns K: Craving - ein ausreichend fundiertes Konzept? (Craving: A concise concept?) Fortschr Neurol Psychiatr 1996;64:4

73a Wetterling T, Veltrup C, Junghanns K: Verlangen nach Alkohol ('Craving') bei Alkoholabhängigen (Craving in chronic alcoholics). Sucht 1998;44:59-64.

73b WHO: International Klassifikation psychischer Störungen. ICD-10. Schulte-markwort. Bern, Huber, 1994.

74 Wittchen HU, Zaudig M, Fydrich T: SKID-I/II strukturiertes klinisches Interview für DSMIV. Users Guide for the Structured Clinical Interview for DSM-IV. SCID-I: First MB, Gibbon M, Spitzer, RL, Williams JBW; SCID-II First MB, Spitzer RL, Gibbon M, Williams, JBW (German modified version/author). Göttingen, Hogrefe, 1996.

75 Workman M, Beer J: Aggression, alcohol dependency, and self-consciousness among high school students of divorced and nondivorced parents. Psychol Rep 1992;71:279-286. 